\title{
Cutting costs - the impact of price-lists on the cost development in the emergency department Ulf Martin Schilling
}

Address: Emergency Department, Linköping University Hospital, Linköping, Sweden

Email: Ulf Martin Schilling - Martin.Schilling@lio.se

from Danish Society for Emergency Medicine: Research Symposium 2009

Copenhagen, Denmark. 26 April 2009

Published: 20 August 2009

Scandinavian Journal of Trauma, Resuscitation and Emergency Medicine 2009, I7(Suppl 2):P2 doi:10.1 I86/I757-724I-I7-S2-P2

This abstract is available from: http://www.sjtrem.com/content/I7/S2/P2

(c) 2009 Schilling; licensee BioMed Central Ltd.

\section{Introduction}

In a recent study it was shown that physicians working at the Swedish emergency department (ED) often are unaware of the real costs for analyses and investigations performed. In this study, the possible impact of price-lists as visual instruments on the overall laboratory and radiology costs at the emergency department of Linköpings university hospital (LUH) was evaluated.

\section{Methods}

Price lists including the 91 most common laboratory analyses and the 39 most common radiological investigations performed at the emergency department of LUH were created by using the information provided by the radiology department and the clinical chemistry department of the hospital. Different modalities (capillary vs. venous blood samples) were listed separately. The lists were distributed to all physicians on-call in internal medicine by the internal email-provider in April 2008. Further lists were exposed above the working stations at the ED continually. The mean costs for laboratory and radiologic investigations for all medical and orthopaedic patients during the months of June and July 2007 and 2008 were calculated. Neither clinical nor admission procedures were changed during the period investigated. The physicians were blinded towards the study. Statistical analysis was performed using the Student's T-test.

\section{Results}

A total of 1442 orthopaedic and 1585 medical patients were attended to during june and july 2007. In June and July 2008, 1467 orthopaedic and 1637 medical patients required emergency service (a total increase of $1,7 \%$ of orthopaedic and 3,3\% of medical patients). The mean costs per patient were 980,27 SKR for orthopaedic and 1081,36 SKR for medical patients in 2007, and in 2008 999,41 SKR $(+1,95 \%)$ and 877,3 SKR $(-18,8 \%)$ respectively. In orthopaedic patients, laboratory costs decreased by $9 \%$ whilst the costs for radiological examination increased by 5,4\%. In medical patients, the costs for laboratory analysis decreased by $21,4 \%$ and for radiological examination by $20,59 \%$.

\section{Conclusion}

The distribution and promotion of price lists as a tool to increase cost awareness at the emergency department resulted in a significant decrease in the investigation costs in the line investigated. It can be concluded that generally available price lists might be an effective tool to cut costs in public health care. 